\title{
Dança: uma potência da mediação cultural na escola
}

\author{
Dance: a cultural mediation power in school \\ Danza: un poder de la mediación cultural en la escuela
}

Recebido: 29/01/2021 | Revisado: 04/02/2021 | Aceito: 08/02/2021 | Publicado: 15/02/2021

Eliane de Oliveira Bittencourt

ORCID: https://orcid.org/0000-0001-7022-7639

Universidade do Vale do Itajaí, Brasil

E-mail: supervisoraeobittencourt@gmail.com

Isleide Steil

ORCID: https://orcid.org/0000-0002-1844-3307

Universidade do Vale do Itajaí, Brasil

E-mail: isleidesteil12@gmail.com

Kátia Franklin

ORCID: https://orcid.org/0000-0002-5645-8411 Universidade do Vale do Itajaí, Brasil

E-mail:katiab@univali.br

\begin{abstract}
Resumo
Este artigo tem como tema a mediação cultural por meio da dança. O objetivo é discutir como a dança pode potencializar a mediação cultural na escola. É um estudo de caráter qualitativo, e utilizou a metodologia Análise Textual Discursiva para a análise dos dados, os quais foram tratados a partir da análise de fotografias. $\mathrm{O}$ artigo discute sobre Mediação Cultural, Espaços e Objetos; Educação Estética e Experiência. Como resultado, sinaliza-se que a mediação em dança possibilita o olhar para essa arte para além de uma atividade física, assim como a simples construção de uma coreografia; instiga os alunos a perceberem suas potencialidades de movimento e de relações consigo, com o mundo, e tudo e todos que estão próximo a eles, e possibilita o aflorar da sensibilidade e da percepção em comunhão com a razão. A dança na escola é uma potência de afetamentos quando desenvolvida por meio do fazer experiência, da educação estética e da mediação cultural.
\end{abstract}

Palavras-chave: Mediação cultural; Dança; Escola.

\begin{abstract}
This article is about cultural mediation through dance. The objective is to discuss how dance can enhance cultural mediation at school. It is a qualitative study, and used the Discursive Textual Analysis methodology for data analysis, which was treated from the analysis of photographs. The article discusses Cultural Mediation, Spaces and Objects; Aesthetic Education and Experience. As a result, it is signaled that mediation in dance makes it possible to look at this art beyond a physical activity, as well as the simple construction of a choreography; it instigates students to realize their potential for movement and relationships with themselves, with the world, and everything and everyone who is close to them, and enables the emergence of sensitivity and perception in communion with reason. Dance at school is an affecting power when developed through experimenting, aesthetic education and cultural mediation.
\end{abstract}

Keywords: Cultural mediation; Dance; School.

\section{Resumen}

Este artículo trata sobre la mediación cultural a través de la danza. El objetivo es discutir cómo la danza puede potenciar la mediación cultural en la escuela. Se trata de un estudio cualitativo, y para el análisis de datos se utilizó la metodología de Análisis Textual Discursivo, que se trató a partir del análisis de fotografías. El artículo trata sobre Mediación Cultural, Espacios y Objetos; Educación y experiencia estética. Como resultado, se señala que la mediación en la danza permite mirar este arte además de una actividad física, así como la simple construcción de una coreografía; incita a los estudiantes a darse cuenta de su potencial de movimiento y relación con ellos mismos, con el mundo y con todo y con todos los que están cerca de ellos, y posibilita el surgimiento de la sensibilidad y la percepción en comunión con la razón. La danza escolar es un poder de afeactar cuando se desarrolla a través de la experimentación, de la educación estética y de la mediación cultural.

Palabras clave: Mediación cultural; Danza; Escuela. 


\section{Introdução}

Com seu passo silencioso dentro das pantufas felpudas, o velho bibliotecário
vinha se aproximando dele. - E isso não é nada-dizia-, leia aqui, ainda
sobre os romanos, o que está escrito, também se poderá pôr isso no
relatório, e isso, e mais isso - e lhe submetia uma pilha de volumes. $O$
tenente começava a folhear os livros e coçava a testa, resmungando: - Santo
Deus! Mas quanta coisa a gente aprende! Quem diria! (Ítalo Calvino, 2010)

Durante o ano de 2019 o grupo de pesquisa "Cultura, Escola e Educação Criadora” da Universidade do Vale de Itajaí UNIVALI - desenvolveu um projeto de pesquisa-ação, numa escola da Rede Municipal de Ensino de Itajaí, com a finalidade de explorar o espaço cultural da escola como potencializadora da educação estética. O projeto desenvolveu inúmeras atividades relacionadas com a música, dança, artes visuais, literatura e também artes integradas direcionadas a revitalização do espaço escolar. Assim como o tenente, imerso à biblioteca em meio a tantos livros, nosso grupo de pesquisa também imergiu na unidade escolar, o que possibilitou o contato intenso com as crianças e adolescentes, nos permitindo inúmeros estudos, discussões e reflexões, “[...] Santo Deus! Mas quanta coisa a gente aprende! Quem diria!” (Calvino, 2010, p. 69).

Desse modo, o presente artigo, que tem o objetivo de discutir como a dança pode potencializar a mediação cultural na escola, como apresenta a Figura 1, é uma fração das ações desenvolvidas, com jovens alunos, por uma das pesquisadoras do grupo, para sua pesquisa de doutorado.

Figura 1. De onde surge o artigo.

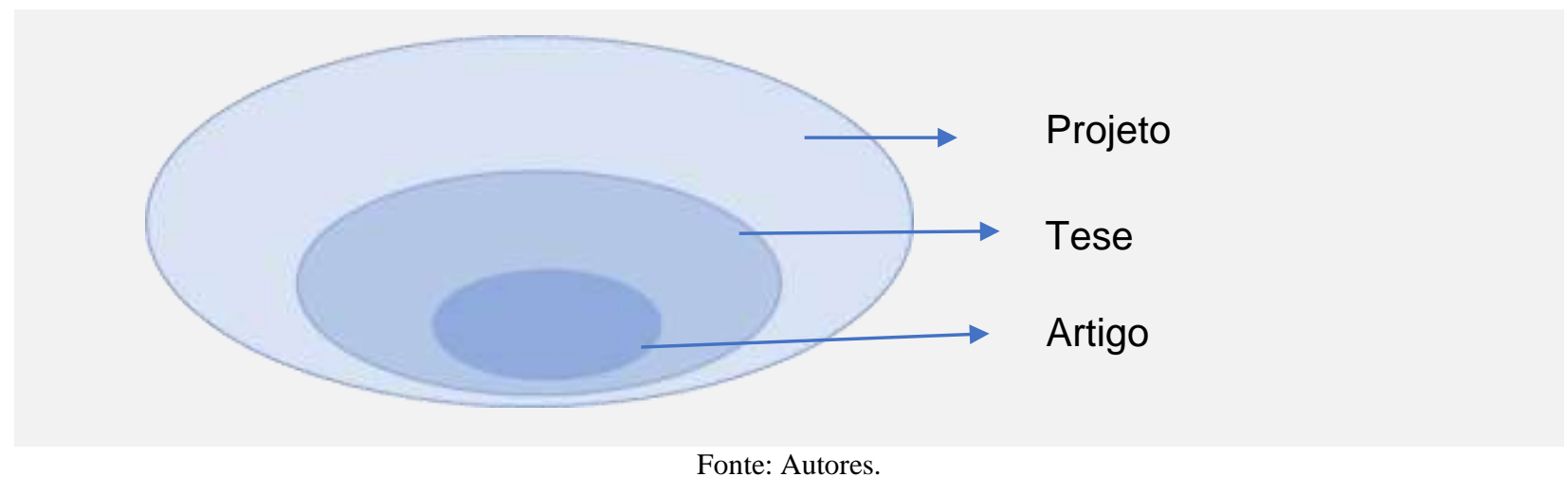

Crispino, o velho bibliotecário do conto "Um general na biblioteca", ao aproximar-se dos tenentes e do general apresentando alguns livros tornava-se um mediador, ao instigá-los, e provocá-los, contaminava-os com novas leituras, possibilitando a ampliação de seus conhecimentos, com isso “[...] encapotados dentro de sobretudos acolchoados para não congelarem, frequentemente eram vistos entrando na velha biblioteca, onde esperava por eles o senhor Crispino com seus livros" (Calvino, 2010, p. 72). Assim como Crispino, que teve a biblioteca e os livros como espaço e objetos propositores, nosso trabalho traz, similarmente, a dança e os alunos em imagens fotográficas captadas em momentos de mediação em dança.

\section{Metodologia}

Caracterizamos esse estudo como uma pesquisa qualitativa, a qual se caracteriza pela "[...] interpretação por parte do pesquisador com suas opiniões sobre o fenômeno em estudo" (PEREIRA et al, 2018, p. 67). A metodologia utilizada é a Análise Textual Discursiva (ATD), que pode ser entendida segundo Moraes e Galiazzi (2017, p. 45) “[...] como um processo 
auto-organizado de construção de novos significados em relação a determinados objetos de estudo [...] é um efetivo aprender, aprender auto-organizado, resultando sempre num conhecimento novo". Logo a ATD sugere a construção de categorias para que por meio dessas partes possa se constituir um todo, ou seja um novo texto. Nesse estudo o processo de categorização se dá por meio de análise de fotografias.

O estudo tem como aporte teórico Moraes e Galiazzi (2007) para tratar sobre a metodologia da Análise Textual Discursiva; Martins et al. (2010), Martins e Picosque (2012), Martins (2005, 2014), Uriarte (2017), Steil e Neitzel (2019) e Franklin (2019) auxiliaram nos diálogos sobre Mediação Cultural, Espaços e Objetos Propositores; Dewey (2010) e Larrosa (2018) contribuíram nas discussões sobre experiência; e Schiller (2015) norteou o estudo sobre educação estética.

Para o desenvolvimento da pesquisa buscamos trazer, por meio das imagens fotográficas, como aconteceram os processos de mediação ocorridos durante as atividades desenvolvidas com o grupo de dança, mediação esta que, entendemos, nos possibilita conhecer, refazer, refletir, mudar e muitas vezes nos desestabilizar e, por que não dizer, nos sensibilizar, pois como nos dizem Barbosa e Coutinho (2009, p.21), por meio da mediação cultural, o contato com a arte é o "[...] caminho para recuperar o que há de humano no ser humano". Logo, a mediação cultural é de suma importância à experiência estética, bem como para o desenvolvimento da educação do sensível. Desse modo, ao se pensar em mediação cultural se faz necessário entendermos o papel do mediador, as proposições, os objetos e os espaços propositores, pois estes podem ser facilitadores ou, até mesmo, inibidores da mediação.

Sendo assim, de acordo com a ATD, as categorias não foram constituídas previamente e sim instituídas a partir de um minucioso olhar sobre as imagens fotográficas. E a partir dessa observação foram criadas quatro categorias que foram agrupadas por unidades de sentidos, possibilitando a análise e criação textual, parte fundamental da produção do presente artigo. As seguintes categorias são: Mediação Cultural, o Mediador, os Objetos Propositores, e os Espaços Propositores.

Sobre as imagens fotográficas é importante ressaltar que elas captam, espacial e temporalmente, recortes de circunstâncias ou de objetos de determinados contextos, o que acaba por corresponder, por semelhança e de forma muito aproximada, aos objetos ou situações registradas, pois, de acordo com Peirce (2003), uma fotografia tem a potencialidade sígnica de corresponder ponto a ponto à natureza fixada. Assim, as imagens fotográficas são carregadas de significados que nos possibilitam sensações, percepções, sentimentos, interpretações e conhecimentos, e, desse modo, ao analisá-las, podemos fazer algumas inferências sobre mediação cultural.

\section{Mediação cultural}

[...] uma ação emancipadora, compreendendo que, ao possibilitar encontros com a arte e a cultura instiga no sujeito um duplo processo: o primeiro ocorre de for para dentro, a partir do contato com um objeto artístico, para a qual ele acessa seus campos perceptivos e sensiveis para promover encontros [...]. (Neitzel e Carvalho, 2016).

Potencializar a relação do sujeito com a arte abre caminhos para a contaminação sensível do olhar, sentir, cheirar, escutar, tocar e se movimentar. Despertar os sentidos é uma das proposições da mediação cultural, que por meio do encontro com a arte incita a reflexão aos modos de ver as relações e o mundo.

Desse modo, podemos dizer que o encontro sensível mediado pelas artes, sejam eles visuais, sonoros, literários ou corporais, provoca a imaginação, percepção, sentimento, pensamento, sobretudo a potência de ressignificar o nosso olhar diante de tais situações vivenciadas, pois de acordo com Martins e Picosque (2012, p. 33) o encontro sensível com a arte nos incita "[...] a ampliar nossa própria significação do ser humano, do mundo, da cultura". 
Nesse sentido, a mediação cultural se constitui quando as pessoas, no contato com arte, estimulam suas emoções, saberes, afeições e apuram os seus sentidos. Para Martins (2005, p. 44) a mediação cultural significa "[...] um encontro, mas não qualquer encontro. Um encontro sensível, atento ao outro. Amplia olhares, ideias, conhecimentos e sensações. Percepção de um mundo que parece já conhecido, mas que se desvela inteiramente novo". Assim, ao levar a dança à escola, foi proporcionado aos alunos sensações, diálogos, trocas, acesso à cultura e apropriações de saberes, isso significa que por meio da mediação com a dança procurou-se contaminá-los esteticamente.

Apurar os sentidos e os modos de fazer, pensar e sentir dança foi um dos objetivos dos encontros na escola. Proporcionar momentos de descobertas corporais e ressignificar o olhar para a dança abre caminhos para o encontro sensível com as relações que se estabelecem, seja com o corpo, com o movimento ou com o outro.

Figura 2. Momentos de mediação cultural.

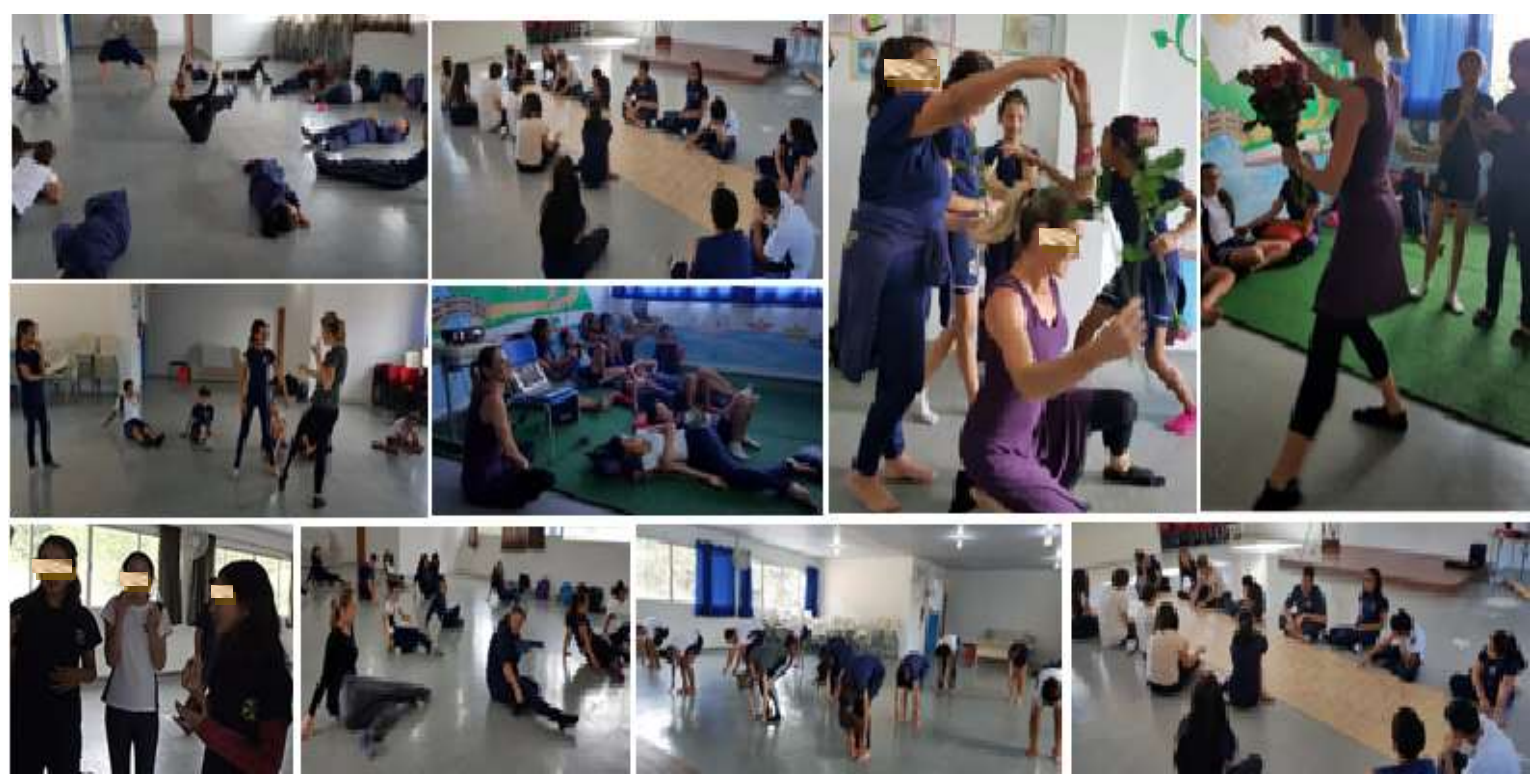

Fonte: Dados da pesquisa

A Figura 2 mostra momentos de mediação em dança, nos quais professora e alunos encontram-se no mesmo espaço, no mesmo acontecimento e em um movimento de trocas. A docente está "entre" os alunos, o espaço, e o aprendizado, em um caminho de ir e vir no papel de professor mediador. Para Martins (2005, p. 54), "mediar é estar entre. Um estar, contudo, que não é passivo e nem fixo, mas ativo, flexível, propositor".

No entanto, é imperioso pensar também no papel do mediador, nos espaços e nos objetos propositores, pois é por meio deles que a dança pode se tonar potencializadora de mediação cultural. Por este motivo trouxemos para análises imagens fotográficas alusivas a essas categorias.

\section{O papel do Mediador}

Mestre não é quem sempre ensina, mas quem de repente aprende. (João Guimarães Rosa, 2001)

Quando Guimarães Rosa, em sua sabedoria poética, se refere ao mestre como uma pessoa que ensina, mas também aprende, que na sua sapiência compreende as experiências, os saberes e as histórias singulares do outro, como fonte de 
conhecimento, ele se refere ao papel de um professor mediador. O sujeito disposto a ensinar, mas também a escutar, trocar, ampliar e ressignificar conceitos, mostra-se um educador sensível capaz de instigar o aluno para experiências estéticas. Dewey (2010, p. 22) anuncia que a experiência estética “[...] não é a contemplação passiva de objetos inertes. É ativa e dinâmica, um fluxo padronizado de energia - em uma palavra, é viva". Logo, a importância do papel do mediador em oportunizar a arte para os seus alunos, pois ela tem o poder de provocar experiências que nos chegam e nos contaminam por meio dos nossos sentidos, receptores de todas as experiências.

De acordo com Dewey (2010, p.45), a arte (especificamente a dança neste trabalho) tem a função de "[...] eliminar o preconceito, retirar os antolhos que impedem os olhos de ver, rasgar os véus decorrentes do hábito e do costume, aprimorar a nossa capacidade de perceber". Observa-se que na Figura 3 todos os alunos, sem distinção de gênero, etnia e padrão corpóreo, participaram das atividades, pois a arte tem a potência de possibilitar a percepção de si e o libertar daquilo que por vezes parece convencional.

Figura 3. $O$ Professor como mediador.

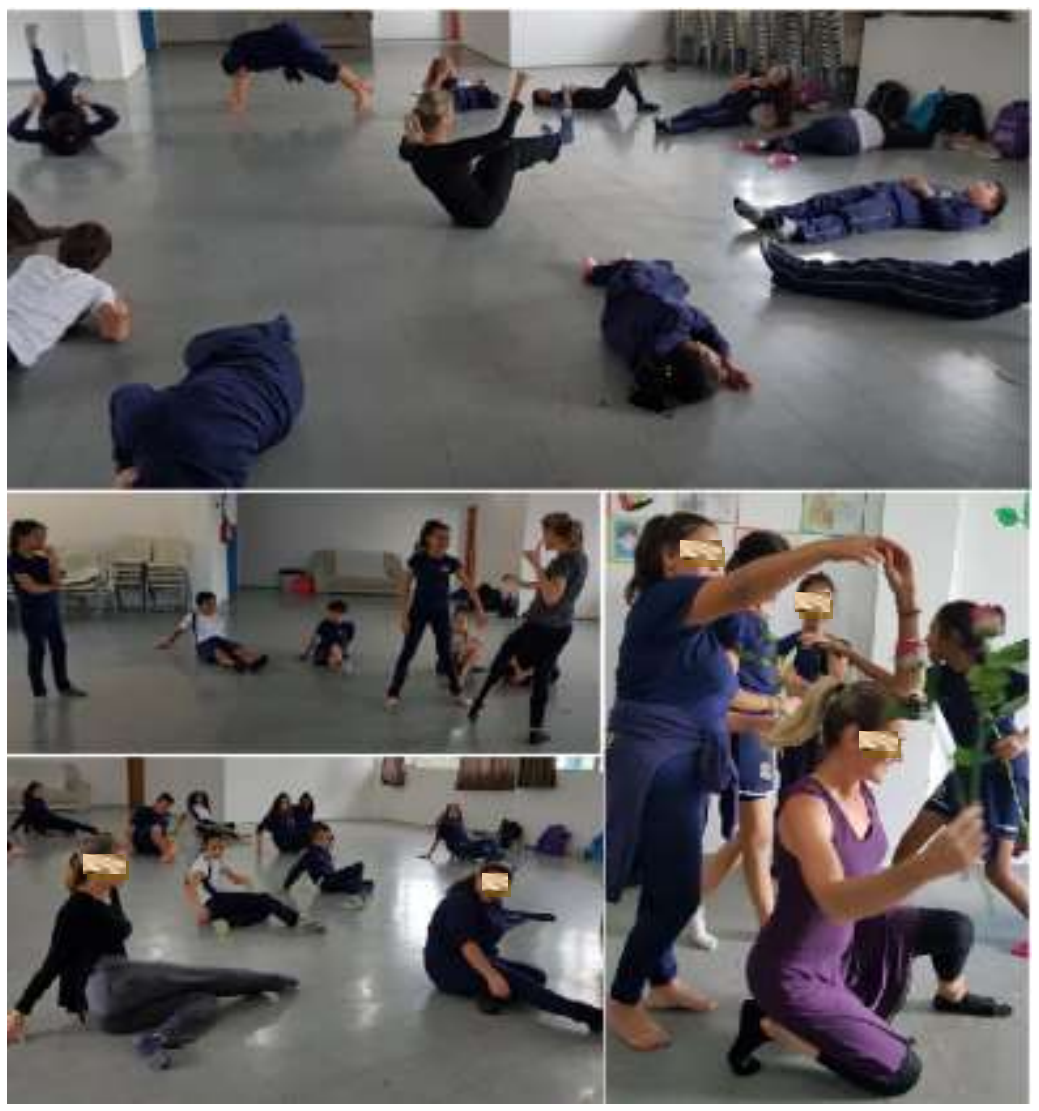

Fonte: Autores.

A Figura 3 também retrata diferentes momentos de mediação, a professora, num movimento de interação e sensibilidade, se dispõe a fazer junto com os alunos as atividades para que se sintam seguros e animados. Isso é muito importante, pois por se tratar de um grupo de adolescentes, podem se sentir acanhados diante dos colegas e desistirem das atividades propostas, ainda mais por serem relacionadas ao movimento corporal e à dança. Logo, a professora sempre atenta $\mathrm{e}$ por meio da mediação, busca envolver e provocar os alunos, possibilitando a todos, mas de modo singular, desenvolverem e potencializarem a educação sensível. Sendo esta tão importante, mas, por vezes, pouco trabalhada nas escolas, devido a sua quase que exclusiva preocupação com o desenvolvimento de conhecimentos pelo viés do racional. 
Schiller (2015) defende que para o homem se tornar cultivado e encontrar sua liberdade perante o mundo, é necessário o equilíbrio entre a razão e a sensibilidade. São duas leis opostas, mas fundamentais ao homem, uma vez que ele só alcança a liberdade quando desenvolve sua racionalidade e sensibilidade, pois “[...] a natureza humana é mista, ou seja, [...] dotada não apenas da razão, mas da razão e sensibilidade" (Schiller, 2015, p.14). É nesse jogo que podemos nos desenvolver plenamente.

À vista disso, o professor mediador, sensível e comprometido com o ensino e a arte, busca nos alunos o apreender do conhecimento sensível e cognitivo. Torna-se um provocador de mudanças, olhares, percepções e entendimentos aflorados por deslocamentos estéticos. De acordo com Steil e Neitzel:

Um educador sensível disposto a ampliar e ressignificar conceitos, leituras e diálogos intra e interpessoais, diálogos com o mundo e com a cultura, é capaz de provocar, de sensibilizar, de ampliar e de modificar conceitos e relações, tornando-se um articulador de transformações. (2019, p. 31).

O mediador pode potencializar, por meio da dança, encontros estéticos para aproximar os educandos da arte e instigar olhares para as singularidades do corpo, das coisas e do mundo por meio do pensar e do sentir. Por meio da percepção do nosso corpo e seus movimentos, refletimos sobre nossa relação íntima, ou seja, entre eu e meu corpo, nas possibilidades de movimentos, deslocamentos, exploração do espaço, na intensidade de força e peso, e na intenção dos meus gestos e da minha dança.

As imagens fotográficas da Figura 2 mostram também a expressão de alegria nos semblantes dos estudantes, isso revela que a realização das atividades não lhes causou qualquer sacrifício, haja vista que quando são realizadas sem a obrigação performativa, mas com liberdade, onde prevalece o respeito às diferenças e às singularidades, as atividades se tornam prazerosas, acessíveis e fruitivas. No entanto, isso se deu porque houve um canal de comunicação e, mais ainda, porque houve a mediação da professora que possibilitou aos alunos o movimento corporal, o encontro com a arte/dança e com a cultura.

\section{Objetos Propositores}

A capacidade performativa e integradora dos objetos e dos espaços propositores oportuniza a mediação porque favorece um conjunto de informações por si só. Faz parte desse conjunto de informações o que trazemos de saberes, anteriores ao encontro com os objetos e espaços, e a esses saberes somam-se aqueles propostos pelo professor mediador por meio de ações corporais, como a dança. Essas propostas podem provocar um conjunto de informações que oportuniza ao sujeito estabelecer relações com o mundo vivido. Segundo Franklin (2019, p. 85) "os objetos e os espaços propositores, quando evidenciados de forma a exaltar as cores, as texturas, as legendas, possibilitam que façamos conexões entre o que sentimos e pensamos para potencializar o entendimento da narrativa".

Em suas ações a professora mediadora, representada na Figura 3 em três momentos distintos, trouxe aos alunos alguns objetos propositores que potencializaram a curiosidade, ludicidade, imaginação e sensibilidade. Porém, alguns desses objetos foram para além das proposições da professora, visto isso na ocasião em que a docente levou uma flor para cada aluno com a finalidade de provocá-los a se movimentar, interagir e dançar; mas como a flor é um objeto poético, afetivo e delicado, provocou nos alunos emoções, criações, sensações e lembranças afetivas.

A função dos objetos e dos espaços propositores é de provocar nossa movência diante do que foi proposto pelo professor, movimento que possibilita afetamento e nos leva à percepção. Segundo Martins (2012), o termo "propositor" concerne tanto às percepções como às informações oferecidas, que podem ser condutoras da forma com a qual o sujeito vai lidar com os conhecimentos, bem como a valoração que vamos atribuir em um processo dinâmico, efetivo e possibilitador da interação do sujeito com o objeto e o meio. A autora afirma que 
[...] objetos propositores podem ser criados para potencializar a mediação: provocando, auxiliando na elaboração de conceitos, mostrando caminhos, diminuindo a distância entre fruidor e obra, entre aluno e professor, tendo em vista provocar uma empatia entre ambos, estimular a imaginação, a percepção, a sensibilidade. (Martins, 2005, p. 129).

Nesse viés, os argumentos referem-se às possibilidades do objeto propositor estimular a imaginação, e provocar a sensibilidade e a percepção, elementos fundantes para uma educação que se preocupe com os sentidos e a sensibilidade não apartados da razão. Quando o professor intenciona que a experiência ${ }^{1}$ seja parte constitutiva do acontecimento sensível entre o sujeito, objeto e o espaço, ele seleciona elementos que sejam propositivos e causem afetamentos.

Figura 4. Os objetos propositores.

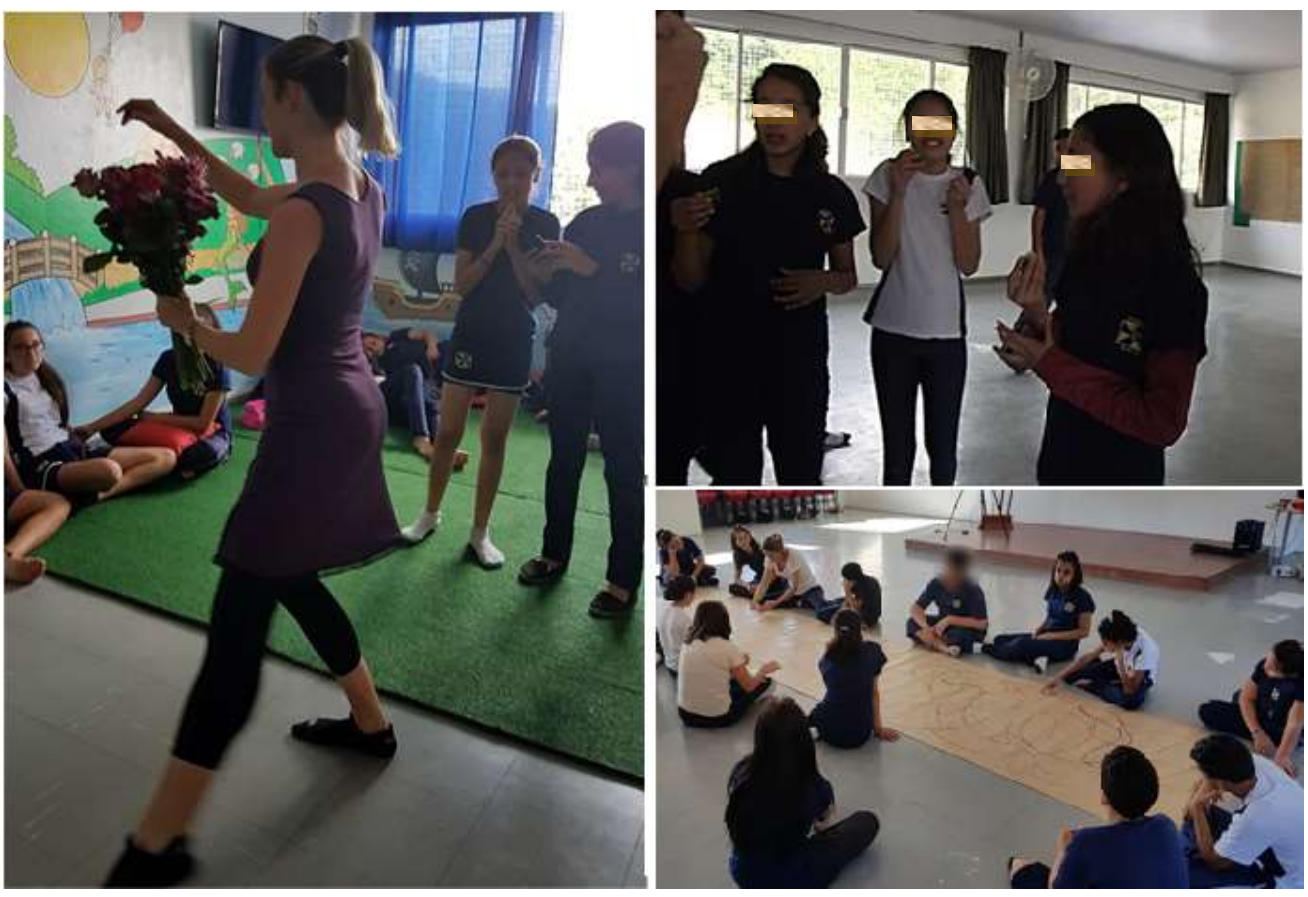

Fonte: Autores.

A professora entrega a flor para um aluno, convida-o para dançar, esse por sua vez entrega outra flor para um colega que também se sente provocado a dançar, logo todos estão em movimento, cada um no seu ritmo, se percebendo, sentindo, dialogando, estimulando e experenciando as potencialidades de seu próprio corpo, bem como ampliando e revigorando a sua educação dos sentidos. Se movimentar a partir da degustação do limão, perceber as sensações que o sabor provocou no corpo e expressá-las por meio da dança, é se permitir ao encontro, ao fazer experiência (Larrosa, 2018). A grafia também foi um objeto propositor utilizado pela professora mediadora, o movimento cria uma obra visual e essa provoca uma outra dança. A relação entre dança e obra visual desloca as percepções para um entre-lugar ${ }^{2}$, uma aproximação que instiga a outros olhares e entendimentos. Neste contexto, podemos dizer que objetos propositores podem promover e potencializar a mediação entre o corpo sujeito e a dança, porque, com isso, possibilitam afetamentos que dependem da capacidade perceptiva de cada indivíduo.

\footnotetext{
${ }^{1}$ De acordo com Larrosa (2018, p. 18) a "experiência é o que nos passa, o que nos acontece, o que nos toca. Não o que se passa, não o que acontece, ou o que toca". Segundo o autor, a experiência é a relação que se estabelece no encontro com algo.

${ }^{2}$ Entre-lugar é um espaço "[...]que se caracteriza por ser fronteira, ou seja, ao mesmo tempo em que separa e limita, permite o contato e aproxima. [...] É lugar de estranhamento e ao mesmo tempo potencializador de identidades. É onde se manifesta de forma mais dinâmica a diversidade de ideias e valores, por isso é propulsor de unidades de posturas. É o lugar cujo horizonte sempre está mais além e aquém, mas é também onde o vazio de significados cobra o estabelecimento de sentidos possíveis”. (Ferraz, 2010, p. 30).
} 
O professor, que utiliza vários objetos e espaços propositores para dialogar com o sujeito e provocar mediações, de modo a possibilitar que o indivíduo construa a sua relação com a realidade, potencializa a ampliação das possibilidades de se ter uma experiência suportada pelo objeto ou espaço, entendidos como uma forma de pensamento, potencializando, assim, a condição de autonomia. Estímulo pretendido é bem-sucedido quando o indivíduo se percebe potencialmente curioso e sensivelmente tocado pelo que reverbera do objeto. Nesse sentido, o objeto propositor pode definir-se como um vetor de significados para o indivíduo quando este se percebe estimulado.

Segundo Soares (2017, p. 145), um objeto propositor é aquele “[...] que provoca um diálogo enriquecedor entre a arte e o sujeito, que envolve pela experiência o desenvolvimento da sensibilidade e instiga novas mediações com ou sem sujeitos e espaços culturais mediadores". O objeto propositor pode ser uma flor, um papel, um fragmento de objeto, um alimento, um perfume, nossa voz, um livro, uma obra de arte, uma música; também pode ser uma imagem fotográfica ou desenhos e até mesmo escritos que estão a nos convidar a sentir e a pensar diante deles. Quando entramos em contato com um objeto, somos convidados a alargar nosso olhar sensível, perceber, ver, desejar a conhecer. O sensibilizar-se está associado ao "[...] sentir-se, ao permitir-se experimentar, vivenciar o excesso, a diversidade de repertório ou permitir-se reconhecer a necessidade de referências estéticas" (Soares, 2017, p. 146).

Muitas são as possibilidades de educação estética por meio de convites da aproximação do sujeito com os objetos ou espaços de dança, pois o apelo sensível é um convite à estesia. Nessa via, os sentimentos, as percepções e os entendimentos dos detalhes podem proporcionar conhecimento. Para Franklin (2019, p.88), por meio da experiência estética o sujeito "[...] pode fazer parte do fenômeno e perceber que, ao sentir e pensar juntos, abre-se um espaço para a reflexão e possibilita a construção de sentidos e de refinamento estético".

A potência dos objetos e dos espaços propositores é evidenciada por Martins (2005) como uma força que provoca ruídos.

Essas forças tendem a provocar ruídos para além do acontecimento, são passíveis de colocar o sujeito da experiência em movimento de busca pelos ruídos, porque aquele zumbido que atinge seu corpo, suas sensações, seus sentimentos, suas expressões; zumbido que entra pelo ouvido e faz tremelicar todo o corpo, dá potência de fala a esse corpo afetado em toda sua intimidade. (Martins, 2005, p. 55).

Os objetos propositores colocam o sujeito em um estado de suspensão propício para o desencadear de reflexão pelo saber exposto, como ressalta a pesquisadora ao comentar sobre o zumbido que faz o corpo tremelicar e dá potência de fala ao corpo. O desejo de contato com o objeto é enriquecido por elementos propositores que ampliam a potencialidade dos espaços e dos objetos provocarem que as pessoas sintam, respirem mais profundamente, acelerem seus pensamentos, suspendam a inspiração, expirem por impulso, transformem o estado de ânimo.

A provocação da ação, ou seja, a conexão que os espaços e os objetos podem potencializar, se dá com boas propostas, com materiais educativos, com espaços e objetos oferecidos, como um atrativo site, uma mídia de divulgação ou a oferta de formação aos educadores ou para a comunidade em geral.

\section{Espaços Propositores}

Os espaços propositores podem ser uma rua, um museu, uma galeria, uma biblioteca, uma escola, espaços públicos ou privados, no entanto esses espaços precisam ser pensados e organizados de acordo com cada instalação, exposição, apresentação, sarau, performance ou atividade escolar, precisam ser pensados para mobilizar, desestabilizar, inquietar, fruir apreciar e provocar encontros. Encontros que, de acordo com Martins e Picosque (2012, p. 13), “[...] germinam sensações, ações, sentimentos, pensamentos [...]. Encontros prazerosos que acolhem com curiosidade e abertura as descobertas e novas 
inquietações [...]". Nesse sentido pensar e preparar os espaços de acordo com cada atividade e experiência é tão importante quanto pensar nos objetos propositores de mediação.

Os espaços, como são pensados e como são apresentados ao sujeito que dança, podem influenciar o modo de como tornar possível a experiência estética, porque a potência de afetamento que lhes é atribuída age provocando uma ação de movência para que ampliemos nossas percepções, e nos leva a ponto de querer saber mais os porquês do mundo. Nesse sentido, em relação aos espaços e objetos propositores "cada retorno é enriquecido com novas experiências e, desse movimento, sob nossa óptica de educação estética, podemos aprimorar nossa forma de agir no mundo". (Franklin, 2019, p. 91).

Entretanto, sabemos que muitas vezes é complexo encontrar nas escolas espaços que promovam a arte e principalmente a dança, que necessita de um espaço amplo e higienizado para que os alunos possam se alongar e se movimentar. Por esta razão, a cada encontro profissionais da escola retiravam as carteiras e higienizavam o auditório para favorecer a realização das atividades. Esse espaço, que até então era um auditório, se tornou um espaço propositor de mediações culturais, e enriquecedor de diálogos, provocando aos alunos experenciarem a dança (Figura 5). Um espaço que tornou possível a mediação cultural e esta, por sua vez, aproximou os alunos da arte e da cultura, nutrindo-os esteticamente. Para Uriarte (2017, p. 115) "a nutrição estética propõe encontros, com produções artísticas em diferentes linguagens apresentadas para alimentar olhares, percepções e pensamentos". 
Figura 5. Espaços Propositores.

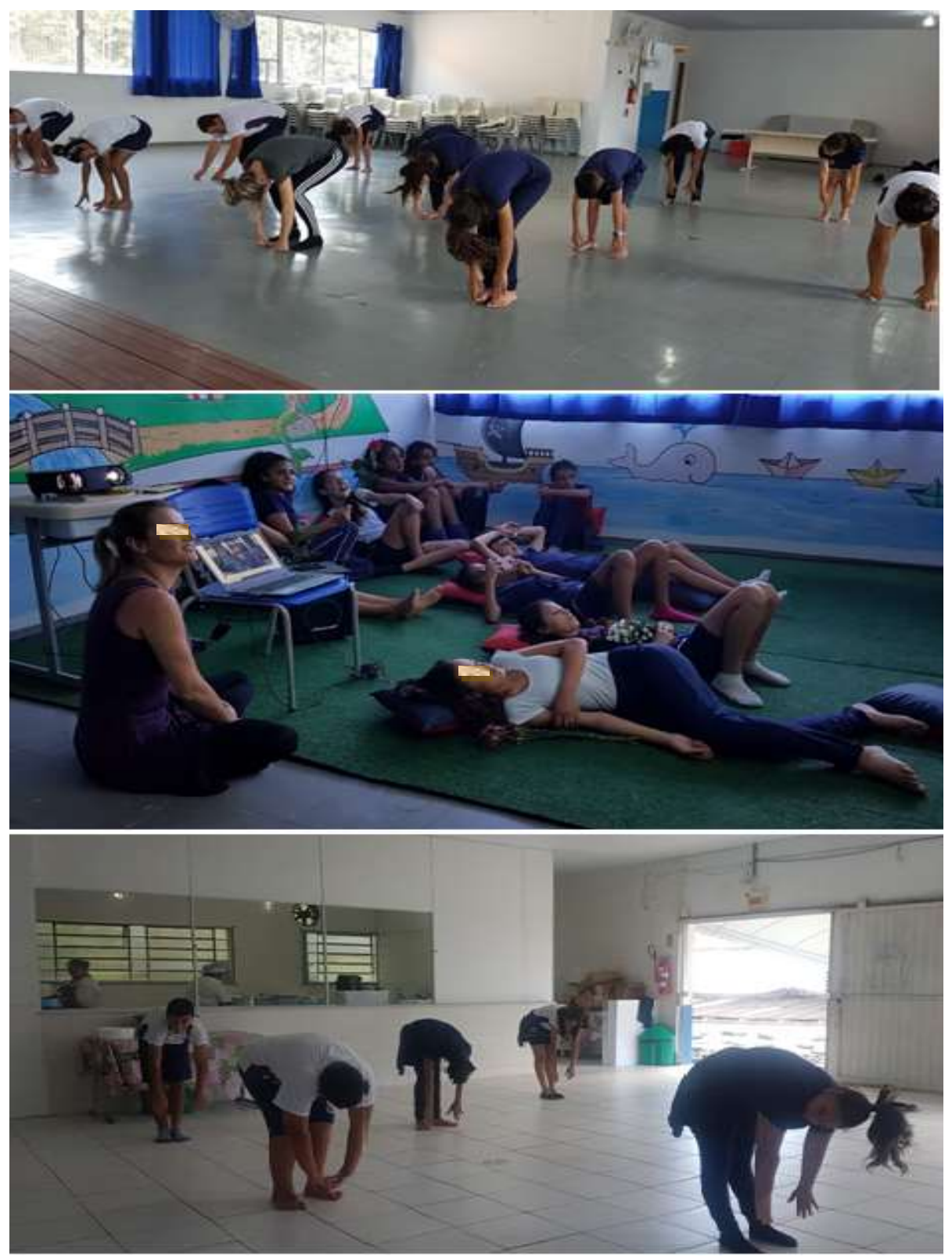

Fonte: Autores.

Em função de outras atividades da escola, a biblioteca e o refeitório também foram espaços utilizados para a dança (Figura 5), são espaços pequenos e, no caso do refeitório, bastante ruidoso. São imprevistos que acontecem na rotina de uma instituição escolar, e que podem ser superados com o olhar cuidadoso e persistente do professor mediador, mas evidencia, e nos faz reiterar, sobre a importância de pensar nos espaços como potencializadores de mediação cultural e educação estética.

\section{Considerações Finais}

A Arte provoca, instiga, e estimula os nossos sentidos, descondicionando-os, isto é, retirando-os de uma ordem preestabelecida e sugerindo ampliadas possibilidades de viver e de se organizar no mundo.

(Kátia Canton, 2009) 
A mediação cultural abre caminhos para a educação estética, para uma educação do sensível, a qual possibilita a aproximação do sujeito com a arte, com o aflorar dos sentidos, e permite o acesso ao conhecimento pelo viés da sensibilidade e da razão. A mediação cultural tem a potência de ressignificar nosso olhar perante o mundo e as situações cotidianas, estabelecendo outros significados para a vida, mas seu êxito está diretamente relacionado ao papel do mediador, e dos objetos e espaços propositores.

Proporcionar outros modos de fazer, pensar e sentir dança foi um dos objetivos nos encontros na escola. A mediação em dança possibilitou olhar para essa arte para além de uma atividade física, assim como a simples construção de uma coreografia. Instigar os alunos a perceberem suas potencialidades de movimento e de relações por meio da dança é possibilitar o aflorar da sensibilidade, da percepção, mas não apartado da razão.

A mediação da professora acolheu os alunos, proporcionando maior interação e segurança na prática da dança, possibilitando que eles se movessem de modo singular e expressassem seus entendimentos corporais a partir das propostas da aula. Por meio dos objetos propositores os alunos ampliaram suas percepções, ressignificaram as funções do sabor, da flor e de uma obra visual, assim como da criação visual. Os objetos propositores moveram os sujeitos para os entre-lugares, e assim vislumbraram as possíveis relações que se pode estabelecer com o mundo vivido. Os espaços propositores nos levam a refletir que é possível mediar a arte da dança mesmo em um refeitório ou na biblioteca, pois os afetamentos propostos se mantêm mesmo em espaços não preparados para a proposta pedagógica.

A dança na escola é uma potência de afetamentos quando desenvolvida por meio do fazer experiência, da educação estética e da mediação cultural. A dança pelo viés perceptivo e criativo possibilita o sujeito ampliar sua relação consigo, com o mundo e com tudo e todos que estão próximos a ele.

\section{Referências}

Barbosa, A. M., \& Coutinho, R. G. (orgs.) (2009). Arte/Educação como Mediação Cultural e Social. São Paulo: UNESP.

Canton, K. (2009). Espaço e lugar. São Paulo: Editora WMF Martins Fontes (Coleção Temas da Arte Contemporânea).

Calvino, I. (2010). Um general na biblioteca. Trad. Rosa Freire d'Aguiar. Schwarcz.

Dewey, J. (2010). Arte como experiência. Tradução Vera Ribeiro. Martins Fontes.

Ferraz, C. B. (2010). Entre-lugar: apresentação. Entre-lugar. Dourados, MS, ano 1, n. 1, $1^{\text {o }}$ semestre.

Franklin, K. (2019). Educação estética: possibilidade no museu de ciências naturais. 2019. 211f. Tese (Doutorado em Educação) - Universidade do Vale do Itajaí, Itajaí.

Larrosa, J. (2018). Tremores: escritos sobre experiência. Autêntica Editora.

Martins, E. C. da S (2018). Potência cultural de quatro bibliotecas francesas: Bibliothèque de la Cité Internationale Universitaire de Paris (CIUP), Bibliothèque Sainte-Geneviève, Bibliothèque publique d'information Centre Pompidou (Bpi) e Bibliothèque nationale de France (BnF). $2018.174 \mathrm{f}$. Tese (Doutorado em Educação) - Universidade do Vale do Itajaí, Itajaí.

Martins, M. C. (org.) (2005). Mediação: provocações estéticas. São Paulo: Universidade Estadual Paulista - Instituto de Artes.

Martins, M. C. et al. (2012). Entre mapas e dobras: mediação cultural na aproximação estética com a cidade. In: CONFAEB ARTE/EDUCAÇÃO: Corpos em trânsito, 22. São Paulo.

Martins, M. C., \& Picosque, G. (2012). Mediação cultural para professores andarilhos na cultura. 2. ed. Intermeios.

Moraes, R., \& Galiazzi, M. do C. (2007). Análise textual discursiva. 2. Ed. Unijuí.

Neitzel, A, Carvalho, C. et al (2016). Mediação cultural, formação de leitores e educação estética. Curitiba: CRV.

Peirce, C. S. (1995). Semiótica. Trad. José T. C. Netto. $2^{\text {a }}$ ed. Perspectiva.

Pereira, A. S. et al (2018). Metodologia da pesquisa científica. 1. ed. UFSM.

Rosa, J. G. (1986). Grande Sertão: veredas. Nova Fronteira.

Schiller, F. (2015). A educação estética do homem. Tradução Roberto Schwarz e Márcio Suzuki. Iluminuras. 
Research, Society and Development, v. 10, n. 2, e27310212477, 2021

(CC BY 4.0) | ISSN 2525-3409 | DOI: http://dx.doi.org/10.33448/rsd-v10i2.12477

Soares, A. F. C. (2017) A cultura e a arte na escola e outras histórias... Appris.

Steil, I., \& Neitzel, A. A. (2019). Por uma escola que dança. CRV.

Uriarte. M. Z. (2017). Escola, música e mediação cultural. Appris. 